\title{
Editorial:
}

\section{Multifaceted and Innovative Answers to Complex Questions in Research on Aging}

As in most fields of scientific enquiry, research on aging typically must be characterized by several core elements: the design must be characterized by strong internal and external validity, excellent measurement, and techniques of analysis appropriate to the hypotheses and data (Mangen, 1995). Increasingly, however, even more is being asked of research on aging. It is now widely recognized that research on aging plays a central role in informing public policy and program decisions. It is also recognized that "the issues relating to seniors policy are complex and immediate ... The factors contributing to the independence or the vulnerability of seniors are multifaceted. The support required to maintain independence or to care for family members is not found uniquely within one or the other of the health or social system but optimally in a blend of these two formal systems with the even more critical informal support networks" (Jeans, 1994, p. 31).

\section{Federal Initiatives in Fostering Methodological Diversity}

Some years ago Health Canada recognized the need to help foster the development of a research environment reflective of this complexity. The development of the Seniors Independence Research Program (SIRP) reflects this recognition. The purpose of SIRP is to promote national research initiatives with a balanced emphasis on social, economic and health determinants of independence for today's and tomorrow's seniors, as a group or individually. To this end, SIRP recently developed a funding initiative known as "Programs of Applied Research". This initiative reflects the goal of federal policy-makers: "to bring together teams which conduct research which broadens our comprehension of these issues" (Jeans, 1994, p. 31).

In April, 1994, the recognition of these issues was taken a step further by the Advisory Committee of SIRP in setting out to organize a Symposium on "Methodological Diversity and Quality in Applied Social and Health Research on Aging and Seniors' Issues". Its purpose was to discuss the diversity of applied research methodologies, their relevance and their respective strengths in the generation of knowledge in the field of aging.

The Symposium brought together over 100 new and experienced Canadian researchers and policy-makers in the field of aging. The Symposium's program and interactive format stimulated considerable enthusiasm amongst participants; this Special Issue is a product of the energy and will of many of those involved in the Symposium to extend the discussion of 
methodological diversity to an even wider audience. Although SIRP developed a Proceedings of the Symposium (SIRP, 1994), many of the presenters at the Conference submitted manuscripts for peer review and revision for this Special Issue.

\section{The Goals of Methodological Diversity}

A goal of this Special Issue is to provide a vehicle for Canadian researchers and educators, policy-and decision-makers, and representatives of seniors organizations themselves, to enhance their level of understanding and expertise in research methodology. Together the papers included in this volume contribute to an increased understanding of some of the innovative and multi-faceted research methods which have been proven effective in the field of aging. Specifically, this volume is intended to push the field of aging in Canada forward in terms of awareness and use of large data bases, qualitative methods, multi-method techniques which combine qualitative and quantitative research methods, action research methods, methods used with health promotion strategies, feminist research methods, and the use of longitudinal studies. In addition, the goals of this Special Issue, as of the SIRP Symposium itself, are to increase awareness of and interest in developing multidisciplinary, collaborative, participatory approaches in research aimed at seniors and age-related issues; to create more awareness of the range, variety and merit of research designs across the spectrum of methods; and to stimulate momentum and interest in multidisciplinary and collaborative research methods.

These objectives assume increasing importance in a research environment wherein some researchers perceive a trend toward "methodological and statistical orthodoxy" (Mangen, 1995, pp. 173-174). As a result, researchers frequently develop a fierce loyalty to a particular methodological framework and members of camps "claim that their approach represents the 'right way' to conduct research ...". David Mangen has recently dismissed such claims as "smacking of hubris," noting that "All methods and all forms of analysis are needed to advance knowledge in the field of aging. Premature closure is not warranted; methods used in combination may yield greater advances" (Mangen, 1995, p. 174). Nevertheless, most scholars spend virtually their entire careers using just one type of research methodology. The call for a combination of methods to advance knowledge in the field of aging is made in several of the papers in this volume.

At the SIRP Symposium, the Minister of Health emphasized the research needs facing her department in fostering "collaborative, multidisciplinary and participatory research" (Marleau, 1994, p. 21). She noted that a prime example of the kind of collaboration - between agencies, national health organizations, universities, hospitals and provincial governments - that will increasingly be required in the future is the Canadian Study of Health and Aging, which has provided valuable national data on the prevalence of dementia, risk factors and patterns of caregiving for persons with demen- 
tia.

Central to many of the research issues addressed in this volume is collaboration in its various forms: between researchers with different disciplinary backgrounds and orientations; between researchers, policy-makers and service providers; and between each of these constituencies and seniors as well.

\section{Multiple Methods in Aging Research}

The paper by Neena Chappell sets the context for many of the ensuing papers in this Special Issue. She broadly describes characteristics of the current climate in terms of the relationship between gerontological research, policy and practice within the constraints of socio-economic realities. Chappell introduces the discussion of the role of qualitative research as a "new hope" for answering many of our questions. The issues she raises are addressed further in subsequent papers by Haldemann and Lévy, Lefrançois and exemplified in the work of Gubrium, and Wood and Kroger. Chappell also notes the increasing emphasis on applied research and the increasing use that will be made of research findings in policy and program areas; this, she argues, will make issues of scientific rigour and replicability of research findings even more important than they currently are. Chappell also discusses some of the pitfalls and practicalities of collaborative research, themes subsequently developed by King and McGowan and Green.

The paper by Verena Haldemann and Ronald Lévy focuses on the legitimacy of multi-method research and on the conditions necessary for achieving high-quality research utilizing multi-methods. In their paper, they discuss the scientific and socio-political contexts from which the movement toward multi-method research has emerged. A central argument of the paper is that comparative analyses are central to the triangulation of methods, and that the triangulation itself requires an external point of reference. As Haldemann and Lévy note, the establishment of new knowledge has always been the fundamental objective of science. They argue that the question of the complementarity between qualitative and quantitative research methods is really a question of scientific goals. They call for the employment of strong constructivist paradigms, even if they are incompatible with positivist paradigms, as represented by quantitative methods.

Richard Lefrançois as well focuses his paper on the issue of multimethods. The paper discusses a range of multi-method approaches such as triangulation and mixed methods. He demonstrates that pluralistic methodology is linked with and reflects the somewhat problematic and developing field of gerontology, and proposes a taxonomy of multi-method strategies. Throughout the paper, the discussion is linked to the interdisciplinary nature of gerontology. 


\section{Qualitative Methodologies}

When the SIRP Advisory Committee, of which I am a member, first discussed the prospect of sponsoring a Symposium on Methodological Diversity, most of the dialogue concerned the role of qualitative methods in collaborative, policy-relevant, applied research. As Haldemann noted in her 1993 Editorial to the Special Issue of the Canadian Journal on Aging/La Revue canadienne du vieillissement on "Qualitative Methods," we have, hopefully, passed the point of having to establish that qualitative research is scientifically credible, robust and rigorous.

Although the papers by Haldemann and Lévy, and Lefrançois, suggest the various ways in which qualitative and quantitative methods may considered to be "complementary" in that they produce knowledge that is different and irreducible that can at the same time clarify different dimensions of one observable fact (Haldemann, 1993, pp. 130-131), the fundamental tension between them has also been noted. "For ... qualitative researchers, standardized questions or structured observations are inherently subject to great variation in interpretation among people. That variation is sufficiently great as to invalidate the entire measurement process" (Mangen, 1995, p. 151). And, as Murphy and Longino (1992, p. 145) have similarly noted, "facts do not reside in absolute space, unencumbered by situational exigencies; data are not pure". The principal objective of qualitative research is the analysis of "the meaning of the experience of individuals, captured in its 'lived' form, with a minimum of preplanned, imposed structure" (Haldemann, 1993, pp. 130-131).

Two papers in this volume, although overtly "qualitative" in their method, differ substantially in their orientation. Linda Wood and Rolf Kroger start with a method, in this case, discourse analysis, and show how it can be applied to gerontological research. Jaber Gubrium, on the other hand, starts with conventional gerontology and focuses on a particular analytical technique within qualitative research, one focused on how experience is given voice in everyday life. The paper discusses the "analytical tension" central to the understanding of voice and narrative on the one hand, and on the contextuality of experience on the other. Conventional methodologies treat these concerns as "procedural problems" and yet, as discussed by Gubrium, they are central features of the observational and narrative methods which he describes.

Gubrium's paper addresses an issue which receives almost no attention in social science research, that is, our need for theories of method. In achieving this end, Gubrium's paper is a highly personal, narrative account. Such detailed accounts of the process of research are much needed in order to advance the understanding of "alternative" methodologies, but they are rarely found in scientific journals.

Jaber Gubrium not only describes the approach he recommends, his paper exemplifies that approach. The paper draws our attention to the ways in which research functions as intervention for good or for ill. The approach 
to research, and to methodology, which Gubrium champions in this paper, and which he well exemplifies in his own extensive body of work, has been adopted by other researchers as well. Barbara Myerhoff's Number Our Days, Jennie Keith-Ross' City of Green Benches, Sarah H. Matthews' The Social World of Old Women, Arlie Russell Hochschild's The Unexpected Community, David Unruh's Invisible Lives: Social Worlds of the Aged and Victor Marshall's (1981) research narrative on participant observation in a multiple-methods study of a retirement community are further exemplars of what researchers have discovered about old age when they keep the narrative and context in analytic tension in their own work.

The paper by Wood and Kroger explores the potential of another type of qualitative methodology, discourse analysis, for understanding issues in aging and in the lives of older people. While the overall purpose of the paper in this volume is to enhance the understanding of the potential relevance of this type of research amongst gerontologists, the paper also contributes to the explication of discourse analysis itself, through its examination of the purposes, methods and accomplishments of discourse analysis, a research area which has, in the words of one review, "often been quite opaque to investigators from closely related fields".

\section{Feminist Approaches}

The relevance of feminist approaches to the study of aging is increasingly recognized in the literature (Lopata, 1995; McDaniel, 1989). The paper by Sheila Neysmith contributes to this discussion. She anchors the principles and assumptions that underlie feminist methodologies in terms of the critical social science tradition and discusses the elemental differences between this tradition and positivism and interpretive schools, reflecting an orientation similar to that adopted by Haldemann and Lévy. Some of the elements of feminist research which Neysmith discusses reflect the increasing recognition, noted by Haldemann (1993, p. 133), of the "illusion of absolute objectivity".

\section{Participatory Action Methodologies}

Because of the dependency of research on values, it is readily understandable why practitioners and seniors ask researchers to work with and not on the individuals being studied and to treat more openly questions of ethics linked to research. It is also vitally important, as Haldemann noted in her 1993 editorial, for researchers to work in the same language as those they are studying in order to obtain more precise information from individuals and also to satisfy ethical requirements by taking into account value systems other than their own. Several papers in this volume relate directly to these concerns. Jean King's paper advocates the importance and usefulness of "practitioner-or-subject-centred action research". Other papers further apply the tenets of action research in their focus on research with special- 
ized populations, as with First Nations peoples (McGowan and Green) and with participants in self-help groups (Lavoie and Dufort).

\section{Longitudinal Studies and Secondary Analyses}

Most discussions of the concept of time within aging research emphasize the age-period-cohort issue, with the usual recommendation and call for more longitudinal research or cross-sequential research designs (Mangen, 1995, pp. 154-155). Recently, the Minister of Health has noted the particular commitment of her department to the more effective use of large databases and the conducting of longitudinal research (Marleau, 1994, p. 21). Two papers in this volume address these issues.

Betty Havens identifies a series of gerontological research questions that demand longitudinal research, and discusses how secondary data analyses are essential to these investigations. The paper by Charlyn Black characterizes and identifies several types of existing large data bases and provides examples of health-related aging research based on their analysis. The potential of such data sets to provide answers to critical research questions in gerontology is well illustrated in the recent Special Issue of the Canadian Journal on Aging $(14: 2,1995)$ on "Policy Issues in Care for the Elderly in Canada".

\section{Research on Specific Populations}

The conduct of research within specific clinical or community contexts, or with particular populations, poses special challenges for researchers. Three papers in this volume address such issues. The paper by Kenneth Rockwood discusses the incorporation of research measures as part of the routine care of geriatric patients, especially if they can be shown to facilitate the processes of care and if the outcomes which they measure reflect outcomes of importance to the patient. Outcome measurement in the health care of the elderly has come of age in an era when randomized, controlled trials are the privileged methodological approach to addressing clinical issues (Robertson, 1994, p. 99). The paper by Rockwood discusses the many challenges to the development and adoption of such measurement tools, and discusses one such instrument designed to measure the effectiveness of specialized interventions. Francine Lavoie and Francine Dufort review questions, designs and methods that can be applied to research on the functioning of self-help groups and consider the unique constraints upon access to such groups for research purposes, given their inherently private and anonymous character. Patrick McGowan and Lawrence Green argue that health promotion and participatory research present challenges and opportunities for extending the benefits of science to populations who have not fully benefitted from innovations available through self-care and mutual aid. 


\section{References}

Haldemann, V. (1993). Editorial: Qualitative Methods: Why? Canadian Journal on Aging, 12(2), 117-138.

Jeans, M.E. (1994). Address. In Proceedings of the Symposium on Methodological Diversity and Quality in Applied Social and Health Research on Aging and Seniors' Issues (pp. 31-32). Ottawa: Seniors Independence Research Program. Lopata, H.Z. (1995). Feminist perspectives in social gerontology. In R. Bleiszner \& V. Hilkevitch Bedford (Eds.), Handbook of Aging and the Family (pp. 114-131). Westport, CT: Greenwood Press.

Mangen, D.J. (1995). Methods and analysis of family data. In R. Bleiszner \& V. Hilkevitch Bedford (Eds.), Handbook of Aging and the Family (pp. 148-177). Westport, CT: Greenwood Press.

Marleau, D. (1994). Address. In Proceedings of the Symposium on Methodological Diversity and Quality in Applied Social and Health Research on Aging and Seniors' Issues (pp. 20-23). Ottawa: Seniors Independence Research Program.

Marshall, V.W. (1981). Participant observation in a multiple-methods study of a retirement community: A research narrative. Mid-American Review of Sociology, 6(2), 29-43.

McDaniel, S.A. (1989). Women and Aging: A Sociological Perspective. Journal of Women and Aging, 1(1/2/3), 47-67.

Murphy, J., \& Longino, C. (1992). What is the justification approach to ageing studies? Ageing and Society, 12, 143-146.

Robertson, A. (1994). Rapporteur: Integration of Research Methods and Outcome Measures. In Proceedings of the Symposium on Methodological Diversity and Quality in Applied Social and Health Research on Aging and Seniors' Issues (pp. 99-100). Ottawa: Seniors Independence Research Program.

Seniors Independence Research Program (SIRP). (1994). Proceedings of the Symposium on Methodological Diversity and Quality in Applied Social and Health Research on Aging and Seniors' Issues. Ottawa: Seniors Independence Research Program. 